Donda, T. \& Lübeck, M. (2020). Escola, Educação Inclusiva e Etnomatemática em Tempos de Isolamento Social. Revista Latinoamericana de Etnomatemática, 13(1), 293-316. DOI: 10.22267/relatem.20131.51

Artículo recebido el 9 de julio de 2020; Aceptado para publicación el 4 de agosto de 2020

\title{
Escola, Educação Inclusiva e Etnomatemática em Tempos de Isolamento Social
}

\section{School, Inclusive Education and Ethnomathematics in Times of Social Isolation}

\author{
Thiago Donda Rodrigues ${ }^{1}$ \\ Marcos Lübeck ${ }^{2}$
}

\begin{abstract}
Resumo
O objetivo neste artigo é apresentar reflexões a partir da análise dos resultados de uma pesquisa realizada com oito docentes da Educação Básica que atuam em contextos socioculturais distintos, como na Educação Escolar Indígena, Educação Escolar do Campo, Educação Especial e Inclusiva, Educação de Jovens e Adultos, entre outras, em diferentes cidades e regiões brasileiras. A intenção é apresentar indícios de como a Educação Escolar está tentando acontecer nestes tempos de isolamento social; quais os desafios e as implicações educacionais enfrentadas pelos educadores e seus educandos; como a Educação Matemática está sendo praticada e; como a Etnomatemática pode ser mobilizada. As informações que respaldam as discussões perpassam as respostas a um questionário encaminhado remotamente e a sua apreciação acontece qualitativamente por meio de aproximações com a análise textual discursiva. Trata-se de uma pesquisa exploratória e os dados indicam que as escolas e os docentes estão atuantes, implementando práticas e aulas remotas usando diferentes tecnologias, apesar das suas limitações e dificuldades, intentando a inclusão de todos com uma Educação Matemática dinâmica e de qualidade, e na medida do possível, mobilizando a Etnomatemática, mesmo diante das adversidades e consequências incertas.
\end{abstract}

Palavras-chave: Escola; Educação; Etnomatemática; Tecnologias; Isolamento; Inclusão.

\begin{abstract}
The objective in this paper is present reflections based on the analysis of the results of a research carried out with eight Basic Education teachers who work in different socio-cultural contexts, such as Indigenous School Education, Rural School Education, Special and Inclusive Education, Youth and Adults Education, among others, in different cities and regions of Brazil. The intention is to present evidence of how School Education is trying to happen in these times of social isolation; what are the educational challenges and implications faced by educators and their students; how mathematics education is being practiced and; how the Ethnomathematics can be mobilized. The information that supports the discussions permeate the answers to a questionnaire sent remotely and its assessment happens qualitatively through approximations with the discursive textual analysis. It is an exploratory research and the data indicate that schools and teachers are active, implementing remote practices and classes using different technologies, despite their limitations and difficulties, trying to include everyone with a dynamic and quality Mathematics Education, and as far as possible, mobilizing the Ethnomathematics, even in the face of adversities and uncertain consequences.
\end{abstract}

Key words: School; Education; Ethnomathematics; Technologies; Isolation; Inclusion.

\footnotetext{
${ }^{1}$ Doutor em Educação Matemática pela Universidade Estadual Paulista (UNESP). Docente na Universidade Federal de Mato Grosso do Sul (UFMS), Paranaíba, Brasil. E-mail: thiago.rodrigues@ufms.br.

2 Doutor em Educação Matemática pela Universidade Estadual Paulista (UNESP). Docente na Universidade Estadual do Oeste do Paraná (UNIOESTE), Foz do Iguaçu, Brasil. E-mail: marcos.lubeck@unioeste.br.
} 


\section{INTRODUÇÃ̃O}

Estamos vivenciando um momento histórico singular, de pandemia global e imprescindível isolamento social. Nossos ambientes de trabalho e pesquisa estão tomados por incertezas e demandas nunca antes vividas ou testemunhadas, e nós precisamos agir, entender o que está acontecendo para tentar abrandar, na medida do possível, os efeitos nefastos disto. Oxalá despertar da inércia, da apatia que pode aniquilar os que não se mobilizam a tempo e de modo sadio. Por isso, como pesquisadores em Educação, precisamos de dados para saber o que está sendo feito, como e o que ainda pode ser praticado, em particular nas escolas públicas, por meio da Educação Matemática e da Etnomatemática, esta enquanto Programa de Pesquisa com fulgentes implicações pedagógicas (D’Ambrosio, 1998; 2002; 2018).

$\mathrm{Na}$ realidade, não faltam temas para serem explorados, contudo, o distanciamento humano nos impele a ficarmos afastados dos ambientes que estávamos acostumados a frequentar e das pessoas com as quais normalmente convivemos presencialmente, uma clausura que ora impõe limites à pesquisa e que só o tempo permitirá transpor com segurança. Por isso, nos colocamos em movimento virtual, buscando pesquisar determinadas questões que podem ser averiguadas desde agora por meio de um questionário enviado para alguns docentes da Educação Básica que atuam em contextos socioculturais peculiares, tais como na Educação Escolar Indígena, Educação Escolar do Campo, Educação Especial e Inclusiva, Educação de Jovens e Adultos, entre outras, de diferentes cidades e regiões do Brasil, e suas respostas que mostramos em excertos, repletos de dados, nos permitem analisar e discutir a temática. A propósito, este artigo relaciona-se com a Educação Inclusiva no sentido lato, tratando de experiências vivenciadas por docentes e discentes na Educação Básica diante das mudanças e desterritorializações irrompidas em decorrência da emergente pandemia, e que teve como consequência um esvaziamento das escolas. E como pensamos que a Educação para Todos não deve ser descontinuada, pois a equidade humana é seu desígnio, o objetivo aqui é saber como a Educação Escolar está tentando acontecer nestes tempos de isolamento social pelas palavras dos seus protagonistas. Sendo assim, depois desta introdução, seguem os aspectos metodológicos, a análise e discussão, as considerações finais e referências desta pesquisa.

\section{ASPECTOS METODOLÓGICOS}


Os desdobramentos metodológicos desta pesquisa adotaram os pressupostos teóricos da investigação qualitativa (Oliveira, 2014). Conforme Lüdke \& André (2003, p. 3), por ser a pesquisa uma atividade social e humana, "claro está que o pesquisador, como membro de um determinado tempo e uma específica sociedade, irá refletir em seu trabalho de pesquisa os valores, os princípios considerados importantes naquela sociedade, naquela época”. Daí, como educadores matemáticos, os valores e princípios que nos orientam estão ligados aos ambientes educacionais, e como o momento atual é crítico para estes meios, buscamos com colegas docentes da Educação Básica saber como eles estão enfrentando a atual conjuntura sanitária, política e educacional, notando que a suspensão das aulas presenciais nas escolas não mitigou seu trabalho, mas o contrário, elevou sua carga e responsabilidade, forçando-os a empreender de imediato ações educativas por vias digitais, como salas de aula virtuais, canais e aplicativos de mensagens, vídeos, plataformas ou programas de videoconferência.

Quanto ao recorte desta pesquisa, pensamos em docentes que atuam em escolas e contextos socioculturais distintos, tais como escolas do campo, indígenas e inclusivas, respeitando os preceitos do Programa Etnomatemática e da investigação qualitativa. Dito isso, segue que:

O Programa Etnomatemática não é uma teoria final, e essa é a razão para considerar essa proposta um programa de pesquisa. É um programa necessariamente transcultural e transdisciplinar e utiliza métodos de pesquisa das ciências, da cognição, da mitologia, da antropologia, da história, da sociologia (política, economia, educação) e de estudos culturais em geral. (D'Ambrosio, 2018, p. 190).

Agora, segundo Bogdan \& Biklen (2006), "a abordagem da investigação qualitativa exige que o mundo seja examinado com a ideia de que nada é trivial, que tudo tem potencial para constituir uma pista que nos permita estabelecer uma compreensão mais esclarecedora do nosso objeto de estudo" (p. 49), isto é, cada acontecimento, informação, pessoa ou história importam. E ainda, “os investigadores qualitativos estabelecem estratégias e procedimentos que lhes permitem tomar em consideração as experiências do ponto de vista do informador" (p. 51), onde "o interesse central dessa pesquisa está em uma interpretação dos significados atribuídos pelos sujeitos à suas ações [...]. Os dados obtidos por meio dessa participação ativa são de natureza qualitativa e analisados de forma correspondente" (Moreira, 2011, p. 76, grifos do autor). Mais, a pesquisa qualitativa, séria e comprometida, “é o caminho para escapar da mesmice. Lida e dá atenção às pessoas e às suas ideias, procura fazer sentido de 
discursos e narrativas que estariam silenciosas. E a análise dos resultados permitirá propor os próximos passos” (D’Ambrosio, 2006, p. 21). Aliás, “a abordagem qualitativa, aplicada pedagogicamente, não constitui nem uma técnica terapêutica nem uma técnica de relações humanas. É, sim, um método de investigação que procura descrever e analisar experiências complexas" (Bogdan \& Biklen, 2006, p. 291).

Logo, na intenção de ouvir e conhecer as experiências de professores da Educação Básica, realizamos uma pesquisa qualitativa considerada exploratória. "Dizemos que uma pesquisa é exploratória ou diagnóstica quando o pesquisador, diante de uma problemática ou temática ainda pouco definida e conhecida, resolve realizar um estudo com o intuito de obter informações ou dados mais esclarecedores e consistentes sobre ela" (Fiorentini \& Lorenzato, 2006, p. 70, grifos dos autores), como é o caso desta pandemia que, de um modo drástico, para alguns dramático, reconfigurou e está reprogramando a vida. Além do mais,

A pesquisa qualitativa pode ser caracterizada como sendo um estudo detalhado de um determinado fato, objeto, grupo de pessoas ou ator social e fenômeno da realidade. [...]. Os dados podem ser obtidos através de uma pesquisa bibliográfica, entrevistas, questionários, planilhas e todo instrumento (técnica) que se faz necessário para obtenção de informações. (Oliveira, 2014, p. 60).

Do exposto, optamos por um questionário. Metodologicamente, “o questionário pode ser definido como uma técnica para obtenção de informações sobre sentimentos, crenças, expectativas, situações vivenciadas e sobre todo e qualquer dado que o pesquisador deseja registrar para atender os objetivos de seu estudo" (Oliveira, 2014, p. 83), que aqui giram em torno de saber como a Educação Escolar Básica está tentando acontecer nestes tempos de isolamento social pelas palavras dos seus principais atores sociais, a saber, os docentes.

O questionário foi elaborado e encaminhado por meio de um formulário eletrônico com seis questões, sendo a primeira de múltipla escolha, na qual indagamos: 1) Você atua como docente na: a) Educação Escolar Indígena; b) Educação Escolar do Campo; c) Educação Especial e Inclusiva; d) Educação de Jovens e Adultos; e) Outra. Os docentes puderam assinalar mais de uma opção e descrever na última alternativa uma resposta mais completa. As quatro questões seguintes foram abertas, nas quais perguntamos: 2) Fale sobre a escola onde você leciona. Como ela está tentando acontecer nestes tempos de isolamento social? Explique/justifique. 3) Descreva os desafios e as implicações educacionais enfrentadas por 
você nestes tempos de isolamento social. 4) Descreva os desafios e as implicações educacionais enfrentadas por seus alunos nestes tempos de isolamento social. 5) Como a Etnomatemática, que leva em consideração as diferentes formas de conhecimento dos alunos, pode ser mobilizada e como a Educação Matemática pode ser praticada nestes contextos socioculturais distintos? Por fim, havia um: 6) Espaço aberto para comentários. Sobre os participantes, sua seleção foi intencional, uma vez que "neste tipo de amostra, o pesquisador decide analisar um determinado fenômeno sem ter a preocupação de fazer generalizações em relação ao universo da pesquisa" (Oliveira, 2014, p. 89). Desse modo, convidamos onze docentes com licenciatura em Matemática e que atuam em um ou mais dos ambientes listados, sendo que oito destes responderam o questionário. E ao fazê-lo deram o seu consentimento para a pesquisa e seus desdobramentos, pois no cabeçalho do mesmo prestamos os devidos esclarecimentos e propusemos manter o seu anonimato. Logo, os docentes e seus feedback foram identificados pela ordem devolutiva dos questionários. Cabe afirmar que, "tratando-se de pesquisa sobre o ensino, a escola e seus problemas [...], as relações entre a escola e a comunidade, enfim toda essa vasta rede [...], ao entrevistarmos professores [...], não lhes estaremos certamente impondo uma problemática estranha" (Lüdke \& André, 2003, p. 36), ou seja, nada do que aqui foi questionado lhes é alheio.

Numa última palavra, vale destacar que a interpretação dos dados do questionário inspira-se na análise textual discursiva, uma vez que "a análise textual discursiva tem no exercício da escrita seu fundamento enquanto ferramenta mediadora na produção de significados [...] (Moraes \& Galiazzi, 2006, p. 118). Complementando, Medeiros \& Amorim (2017, p. 250) dizem que, na análise textual discursiva, “[...] descrição e interpretação são vistas também como elementos da análise [...]. A interpretação [...] não adota exclusivamente uma teoria específica do início ao fim, pois, vislumbra, na maior parte das vezes, produzir teorias no processo da investigação.” Isto é plausível, já que nas pesquisas em Educação Matemática e Etnomatemática nós também não nos aprisionamos em gaiolas teóricas perpétuas.

\section{ANÁLISE E DISCUSSÃO}

Com frequência, a Educação Inclusiva é associada ao processo de inclusão de alunos com deficiência no ambiente escolar. No entanto, a ideia de uma Educação Inclusiva tem uma perspectiva mais ampla e deve levar em conta outros grupos que também sofrem processos 
de exclusão. Em outras palavras, é uma Educação para Todos, sem exceção. A Declaração Mundial de Educação para Todos já ressaltava que nenhum grupo, seja ele qual for, "deve sofrer discriminação no acesso às oportunidades educacionais" (UNESCO, 1990, p. 2).

Ratificando a ideia de Educação Inclusiva, o relatório Diretrizes para Inclusão: garantindo o acesso à Educação para Todos, da UNESCO, reforça que a Educação deve garantir o desenvolvimento humano de Todos, independente das barreiras que promovam a exclusão no âmbito educacional, e os aspectos físicos, sociais e emocionais não podem ser nisto um desqualificador. "A inclusão, portanto, envolve a adoção de uma visão ampla da Educação para Todos, abordando o espectro de necessidades de todos os alunos, incluindo aqueles que são vulneráveis à marginalização e exclusão" (UNESCO, 2005, p. 11). Como exemplo de grupos vulneráveis/excluídos/marginalizados, o referido relatório cita crianças abusadas, trabalhadores infantis, refugiados ou crianças desabrigadas, migrantes, minorias religiosas, trabalhadores infantis domésticos, crianças atingidas pela pobreza, minorias linguísticas, minorias étnicas, crianças de rua, crianças em zonas de conflito/crianças soldados, crianças com deficiência, crianças nômades, órfãos HIV positivos.

Assim, nossa noção de inclusão, orientada similarmente pelas ideias da Etnomatemática, se alinha a essa concepção ampla, no sentido de que

[...] podemos chegar a uma Educação Inclusiva, a partir da mudança radical do modelo educacional, e receber a Todos, independentemente de sua particularidade, seja ela de caráter biológico, sensorial, intelectual, social, cultural, econômico e/ou político. Isso implica uma concepção de Educação que compreenda todas as necessidades educacionais dos alunos; que não tenha um arquétipo de estudante; que não exija de ninguém qualquer adaptação para que dela participe; que a sua práxis contemple a todos sem que seja necessário desenvolver procedimentos especiais para lidar com alguns; que o currículo leve em consideração as particularidades ambientais e pessoais, e também garanta a qualidade de ensino [...].(Rodrigues \& Lübeck, 2018, p. 3).

Ainda que a noção de grupos vulneráveis não seja implicada necessariamente pela pobreza, a condição econômica é um fator importante, e muitas vezes determinante, e deve ser considerada quando buscamos combater processos excludentes. A exemplo, em Rodrigues (2017) foram problematizados processos de exclusão impostos pela Matemática e a seleção a partir dela, que também são verificados nos demais âmbitos sociais. Na realidade,

O processo de seleção ainda leva em conta a condição social, cultural, econômica e biológica [...] de forma que se tenha no final do processo algo muito parecido com o 
Donda, T. \& Lübeck, M. (2020). Escola, Educação Inclusiva e Etnomatemática em Tempos de Isolamento Social. Revista Latinoamericana de Etnomatemática, 13(1), 293-316. DOI: 10.22267/relatem.20131.51

estereótipo [...] "homem, branco e europeu". Para tanto, indígenas, quilombolas, pessoas com deficiência, mulheres, mas sobretudo pobres, são excluídos durante o processo de decantação ou nas melhores das hipóteses, têm um caminho muito mais difícil que os "eleitos". Nunca é demais frisar que a pobreza é um fator determinante no processo de seleção, mesmo que o sujeito não se enquadre, por exemplo, nas características de ordem cultural ou biológica, se for rico, pode superar a seleção. (Rodrigues, 2017, p. 154).

Inegavelmente houve avanço, tanto no âmbito internacional quanto no contexto brasileiro, rumo a uma Educação que não exclua ninguém, o que pode ser verificado nos acordos internacionais, leis nacionais, políticas públicas, desenvolvimento de pesquisas em diversas frentes etc., no entanto, há muito a fazer, pois ainda 258 milhões de crianças, adolescentes e jovens em idade escolar estão fora da Educação Primária e Secundária no mundo, pelo relatório Pobreza na Infância e na Adolescência, elaborado pela UNICEF em 2018. Assim, em um país com as dimensões do nosso, os avanços não são equitativos em todas regiões e em muitos lugares as desigualdades são profundas, o que pode ser agravado pela pandemia. Segundo o Relatório de Monitoramento Global da Educação da UNESCO de 2020,

Nunca foi tão crucial tornar a educação um direito universal e uma realidade para todos. Nosso mundo, em rápida transformação, enfrenta grandes desafios - das rupturas tecnológicas à mudança climática, passando por conflitos, deslocamento forçado de pessoas, intolerância e ódio - que ampliam ainda mais as desigualdades e terão impacto nas próximas décadas. A pandemia da COVID-19 expôs e aprofundou ainda mais essas desigualdades e a fragilidade de nossas sociedades. (UNESCO, 2020, p. 5).

Aliás, a crise gerada pela pandemia poderá acentuar as diferentes formas de exclusão e o mundo poderá sofrer "uma perturbação de grandes dimensões e sem precedentes na história da educação. As diferenças sociais e digitais colocam os mais desfavorecidos em uma situação na qual correm o risco de ter perdas de aprendizagem ou abandonar a escola" (UNESCO, 2020, p. 5). Além disso,

As respostas à crise da COVID-19, que afetou 1,6 bilhão de estudantes, não deu atenção suficiente à inclusão de todos os estudantes. Enquanto $55 \%$ dos países de renda baixa optaram pelo ensino a distância online na educação primária e secundária, apenas $12 \%$ das famílias nos países menos desenvolvidos têm acesso à internet em casa. Mesmo abordagens com baixo uso de tecnologia não são capazes de assegurar a continuidade da aprendizagem. Entre os $20 \%$ mais pobres das famílias, apenas $7 \%$ possuem um rádio na Etiópia, e nenhuma possui um aparelho de televisão. No geral, cerca de $40 \%$ dos países de renda baixa e média-baixa não apoiam estudantes em situação de risco de exclusão. Na França, até 8\% dos estudantes perderam contato com os professores após três semanas de confinamento. (UNESCO, 2020, p. 14). 
Nesse sentido, devemos considerar que um cenário que, apesar dos avanços, ainda exclui e está sendo ainda mais prejudicado pela crise gerada pela pandemia da COVID-19, a adoção do ensino a distância, mesmo sendo uma importante solução emergencial, igualmente acentua desigualdades já existentes e gera novas barreiras motivadas, por exemplo, pela falta de acesso a equipamentos e à rede de internet, dificuldade apresentada pelos alunos da Educação Especial em acompanhar as atividades remotas, falta de capacitação do professor para lidar com essa forma de ensino, dentre outros.

Em vista disto, buscamos dados com o objetivo de subsidiar algumas reflexões que estamos realizando nestes tempos de afastamento humano no que tange a Educação Matemática em contextos específicos. E com o título Desterritorialização, Educação e Etnomatemática em Tempos de Isolamento Social, encaminhamos um questionário para onze docentes da Educação Básica esperando contar com o seu importante apoio quanto ao preenchimento do mesmo. Pedimos a gentileza de responderem e antecipadamente prestamos nosso respeito e agradecemos sua valiosa colaboração, mesmo sabendo que todos estão bastante ocupados. E dos oito docentes que responderam o questionário, dois deles atuam na Educação Escolar Indígena (Docentes 3 e 6); outro atua na Educação do Campo (Docente 8); dois atuam na Educação Especial e Inclusiva, com alunos com laudo, sendo um no Ensino Fundamental Anos Iniciais (Docente 2), e outro no Ensino Fundamental Anos Finais e Ensino Médio, (Docente 1); na Educação de Jovens e Adultos, com o Avanço do Jovem na Aprendizagem, atua um (Docente 4); e na Educação em Tempo Integral, em Escolas da Autoria, atuam os demais (Docentes 5 e 7). Importa destacar que, para todas as opções desta primeira questão, houve pelo menos um participante. Outro fato é que todos são docentes de escolas públicas, do sul e centro-oeste do Brasil, e é sobre pessoas como estas, um corpo profissional assim, estudioso, pujante e comprometido, de ombros calejados, que recai a responsabilidade de carregar nosso país para dias melhores, via de regra pelo esforço do coletivo, mas, acima de tudo individual, apesar das carências materiais, estruturais e tecnológicas persistentes, bem como das adversidades sanitárias e políticas surgidas e acentuadas ultimamente.

Na segunda questão do questionário pedimos: Fale sobre a escola onde você leciona. Como ela está tentando acontecer nestes tempos de isolamento social? Explique/justifique. Nas respostas dos docentes, ao falarem sobre suas escolas, um fato foi unânime, de que todas 
Donda, T. \& Lübeck, M. (2020). Escola, Educação Inclusiva e Etnomatemática em Tempos de Isolamento Social. Revista Latinoamericana de Etnomatemática, 13(1), 293-316. DOI: 10.22267/relatem.20131.51

estão seguindo as medidas de prevenção e segurança e as recomendações de isolamento social definidas pelos municípios e estados. Outro dado importante é que todas as escolas estão tentando acontecer, apesar do isolamento. Escolas indígenas, do campo, da periferia das cidades; escolas com mil alunos ou mais, outras menores; funcionando em turnos; em implantação; com e sem tecnologia, internet, computadores; enfim, independente de tudo o que está posto, as escolas e os docentes estão atuantes. E lendo os relatos, podemos saber melhor como isso está acontecendo, pois a forma pode diferenciar de um local para o outro, mas, em todos, os docentes estão preocupados com os discentes. Em vista disto, a Educação Escolar, antes presencial, "está acontecendo através da plataforma Google sala de aula, uso do Meet, vídeo aulas, atividades impressas para alunos que não possuem acesso e via WhatsApp" (Docente 4, comunicação pessoal, junho 15, 2020). Deste modo, dizem que:

Estamos atendendo os alunos pelo formato de ensino remoto [...]. No entanto, alunos sem condições de acesso às tecnologias (sinal digital de Televisão, Smartphones, notebook, internet) tem direito ao material impresso, sobre as aulas postadas na sala virtual. Esses alunos sem acesso aos meios tecnológicos retiram semanalmente na escola o material impresso com as atividades de todas as disciplinas e as devolvem na semana seguinte. (Docente 1, comunicação pessoal, junho 11, 2020).

Podemos observar que, apesar de o ensino a distância online ser uma importante solução de emergência, não consegue chegar a todos, sendo necessário a confecção de atividades impressas aos que não possuem equipamento e rede de internet, mas que, no entanto, ficam privados, por exemplo, das explicações realizadas em ambiente virtual pelos professores e da interação que pode ser feita por videoconferência. Essa é uma nova barreira que pode gerar exclusões pela dinâmica imposta durante a pandemia. Esse cenário é recorrente em outras respostas, como segue:

A escola onde estou lotado nesse ano escolar passou a funcionar pelo Programa Escola da Autoria em Tempo Integral. [...]. É uma escola localizada em uma parte periférica da cidade e com dificuldade de acesso a tecnologias digitais e bens materiais como celulares [...]. A princípio usamos o aplicativo WhatsApp formando grupos das salas de aulas [...] para finalizar o primeiro bimestre [...]. No segundo bimestre a escola passou a utilizar o [...] Google sala de aula, Gmail e o aplicativo Meet. (Docente 5, comunicação pessoal, junho 15, 2020).

Assim, como dito acima, o relato seguinte nos mostra também que nem todos estão tendo possibilidade de ter o acompanhamento realizado virtualmente e que a escola está buscando contornar essa dificuldade oferecendo equipamentos e a sala do laboratório de informática 
para os alunos, mas que também pode representar um perigo de contágio, tendo em vista a necessidade de deslocamento dos alunos, a interação, mesmo que mínima, entre pessoas e a manipulação de objetos de uso comum, como computador, mesas e cadeiras. Notadamente,

A escola está com as aulas remotas [...] e utiliza a plataforma Google sala de aula para realizar aulas online em horário reduzido, essa redução é feita de modo que os professores tenham contato online com o estudante pelo Meet em uma aula na semana. As demais aulas são destinadas para atendimento individual para sanar dúvidas ou promover outras abordagens, sejam elas realizadas pelo WhatsApp pessoal dos professores, do grupo da turma no aplicativo e ainda pelo mural do Google sala de aula. A partir das aulas, a escola propõe que os professores elaborem uma Atividade Pedagógica Complementar (APC), ou seja, é proposta uma atividade a cada 15 dias [...]. Essa proposta busca viabilizar a execução das atividades pelos estudantes que necessitam da versão impressa da atividade e não possuem acompanhamento [...]. A escola tem produzido diversos relatórios [...], que em parte auxiliam a entender o comportamento dos estudantes e professores diante o distanciamento social. [...]. Para acompanhamento das atividades também utiliza como recurso os tutores. [...] e estudantes que estão sem conectividade tiveram horários agendados para utilizar a sala de tecnologias da escola, e dentre eles estão estudantes do abrigo e com alguma vulnerabilidade social. (Docente 7, comunicação pessoal, junho 15, 2020).

Como podemos notar, dependendo do contexto socioeconômico onde a escola está inserida, a opção de manter as aulas online pode implicar em barreiras rígidas, difíceis de serem transpostas e a perda de aprendizagem será certa. O próximo docente explicita bem isso ao relatar como estão sendo as atividades com estudantes indígenas:

A escola onde trabalho está localizada na aldeia indígena [...], e nestes tempos de pandemia a escola está fechada como todas as outras em nosso estado. Infelizmente os alunos que lá residem não tem acesso a internet e muitos não têm acesso nem mesmo a televisão, o que dificulta muito a aprendizagem nesse momento tão crítico. Para que os alunos não fiquem sem nenhuma forma de estudo, a cada semana, os professores elaboram atividades voltadas ao cotidiano dos alunos dentro de sua disciplina para enviar aos alunos, e quem está fazendo a organização e distribuição destas atividades são os professores indígenas que lá residem. (Docente 6, comunicação pessoal, junho $15,2020)$.

Nestes excertos, observamos que as aulas a distância online são uma via de mão-dupla, pois ao mesmo tempo que possibilitam a continuidade de atividades durante o isolamento social e promovem o acesso de muitos à Educação Escolar, também criam barreiras para o acesso e excluem vários outros, e dentre os fatores para essa exclusão, temos: indisponibilidade do serviço de internet na região em que o estudante mora; pacote de internet muito limitado para a realização das atividades; indisponibilidade de equipamentos para acesso à internet, 
pois, muitas vezes, os equipamentos são dos pais ou responsáveis, e não estão totalmente disponíveis aos estudantes ou em quantidade suficiente para a demanda; e impossibilidade econômica de ter um equipamento para acesso à rede. Aliás, na comunidade indígena, “[...] a realidade se mostra de bastante carência [...] e nem todos moradores possuem condições de adquirir e acompanhar a tecnologia do momento. As famílias que adquirem certas tecnologias, como telefone celular, por exemplo, costumam emprestar o aparelho para quem não possui" (Kaminski, Ribeiro, Lübeck \& Boscarioli, 2019, p. 101). Estas condições instauram processos de exclusão que se agravam diariamente neste contexto de pandemia. Para discutirmos a abrangência das tecnologias no Brasil, nos remetemos aos dados de uma pesquisa finalizada pelo Instituto Brasileiro de Geografia e Estatística - IBGE em abril deste ano, que aponta que 20,9\% dos domicílios brasileiros - cerca 46 milhões de pessoas ainda não têm acesso à internet, e que essa proporção é bem maior na zona rural, chegando a 50,8\%. Dentre os motivos para o não acesso, a pesquisa apurou que $11,8 \%$ consideram o serviço de internet caro e 5,7\% consideram caros os equipamentos para o acesso - celular, notebook e tablet. Sem dizer que para $4,5 \%$ das pessoas que não têm acesso, o serviço não está disponível na região em que se situam. Se pegarmos somente a zona rural, esse índice sobe para 12\% (IBGE, 2020). Em relação ao acesso a equipamentos que possibilitam a conexão à internet, o IBGE (2020) também apurou que apenas 41,7\% dos domicílios brasileiros possuem microcomputador e 12,5\% tablet, e são menos frequentes nas áreas rurais, sendo $14,3 \%$ e 3,8\% respectivamente. O relatório do Comitê Gestor da Internet no Brasil aponta que o acesso à rede nas camadas mais pobres acontece sobretudo por meio do celular, e que,

Apesar de ser cada vez mais frequente os domicílios brasileiros contarem apenas com o acesso à Internet, sem a presença do computador, essa é uma configuração que ocorre principalmente entre aqueles de classes mais baixas. [...]. Entre os domicílios de classe C, $43 \%$ tinham computador e Internet e 33\% tinham apenas a conexão à Internet. Já entre os domicílios das classes $\mathrm{D}$ e $\mathrm{E}$, a maioria não possuía acesso ao computador e nem à Internet $(58 \%)$ e mais de um terço (34\%) tinha acesso apenas à Internet. (Comitê Gestor da Internet no Brasil, 2019, p. 107).

Com vemos, apesar de não podermos atribuir totalmente a questão econômica a motivação para esse tipo de exclusão, a pobreza é um importante fator para o não acesso à internet e promove a exclusão deixando sem estudos milhões de alunos neste momento de pandemia. 
Adiante, na terceira questão pedimos a cada docente: Descreva os desafios e as implicações educacionais enfrentadas por você nestes tempos de isolamento social. Algumas respostas foram: "ensinar sem poder olhar no rosto do aluno [...] não saber a resposta dele [...] criar maneiras para substituir tudo o que era material concreto na sala de aula pelo virtual, meu quadro de giz agora é a câmera do celular, do notebook" (Docente 1, comunicação pessoal, junho 15, 2020); também, “desenvolver situações cotidianas que não faziam parte de nossa realidade social, distanciamento social, não interagir com as pessoas de forma presencial" (Docente 3, comunicação pessoal, junho 15, 2020); em complemento, “o grande desafio encontrado neste momento é não poder estar ensinando aos alunos presencialmente, pois sabemos de toda dificuldade encontrada quando trabalhamos em sala de aula, o que significa que longe [...] os alunos encontram muita dificuldade para aprender" (Docente 6, comunicação pessoal, junho 15, 2020); e mais, "replanejar aulas, aprender a usar novas tecnologias, buscar novos modos de avaliar a aprendizagem, a interação professor-aluno, abordagem aos estudantes, tudo isso" (Docente 4, comunicação pessoal, junho 15, 2020); e o "desafio de tentar atender todos os alunos e tentar motivar os alunos com as aulas a distância" (Docente 8, comunicação pessoal, junho 15, 2020). E não para por aí, sendo que:

Os desafios foram muitos e acumulados com o medo de uma pandemia nunca vista no país [...]. Mas alguns desafios foram aumentados [...], o primeiro [...], fui para uma nova escola, onde trabalhei presencialmente menos de 30 dias, isso dificulta conhecer os alunos [...]. Outro desafio foi elaborar um relatório dos alunos que têm acesso a internet, dos que precisam de ajuda para acessar a plataforma online ou aplicativo e dos alunos que precisam de atividades impressas [....]. E um dos piores, escutar de uma mãe que seu filho não irá usar o Google sala de aula, pois o celular não o comporta por causa de um jogo [...]. (Docente 5, comunicação pessoal, junho 15, 2020).

Por fim, podemos acrescentar a esta seção de relatos um último, o qual afirma que:

Os profissionais, no geral, estão trabalhando além da carga horária [...]. Alguns benefícios foram cortados [...]. Os profissionais estão sujeitados a se exporem online, gravando áudio e vídeo sem pagamento ou consentimento de seus direitos autorais [...]. O profissional está abalado com a quantidade de informações e a forma de imposição para aceitação das TICs [...]. Muitos profissionais têm se queixado [...] do trabalho pedagógico duplicado [...]. Além disso, conta a questão de cuidar dos filhos e familiares [...]. Problemas de conectividade [...], nossos recursos tecnológicos pessoais estão ficando obsoletos, celulares parando de funcionar, obrigando os professores a comprarem outros aparelhos; notebooks que não aceitaram o e-mail institucional e a plataforma [...]. Cursos (webinar), que na sua maioria, não contribuem para o fazer pedagógico [...] e empresas vampiras, que são potenciais promotoras da iniciativa 
privada, que estão dando pitaco na educação [...]. Enfim, estamos desgastados e cansados de receber ordens de quem nunca esteve no chão da escola pública como professor. (Docente 7, comunicação pessoal, junho 15, 2020).

$\mathrm{O}$ isolamento social mudou drasticamente a forma de trabalho dos professores, e as novas demandas não somente trazem uma necessidade de trabalhar sozinho, o que já é inusitado tendo em vista que, tradicionalmente, os professores tem seus interlocutores presentes, mas também habilidades em tecnologias digitais desconhecidas por muitos. Essa é uma questão que merece atenção, pois os professores, salvo certas exceções, constitui todo seu repertório didático-pedagógico a partir da interação presencial com os alunos e a mudança do presencial para o online não é simples, exige formação, planejamento e tempo. Nesse sentido, Shimazaki, Menegassi \& Fellini (2020, p. 9) discutem que "uma das causas que torna o ensino remoto mais difícil é a falta de formações na área de Tecnologias da Informação (TI), pois os professores não são tutores, como na educação a distância [...] [que] envolve atuações dirigidas, tanto de orientação pessoal, quanto acadêmica e profissional". Aqui, devemos pontuar ainda que os professores estão enfrentando problemas em relação a equipamentos e à internet, e indubitavelmente, muitos se enquadram em grupos que, por questões econômicas, enfrentam dificuldades de acesso, tendo em vista os baixos salários pagos aos professores no Brasil, situação agravada com a diminuição da renda neste período de pandemia por perdas de aulas, cortes de benefícios, aumentos de gastos, dentre outros. Mas é preciso seguir em frente e tentar sobreviver a tudo isso.

Como antes, pedimos a cada docente, agora na quarta questão, que: Descreva os desafios e as implicações educacionais enfrentadas por seus alunos nestes tempos de isolamento social. E como as realidades envolvidas são distintas, também os desafios foram diferentes, tais como "motivação para continuar os estudos, pois como muitos dos alunos tem trabalho nas fazendas, estão deixando os estudos de lado para poder ajudar as suas famílias nesse período de dificuldade" (Docente 8, comunicação pessoal, junho 15, 2020). Além disso, na cidade também "não tem sido fácil para os estudantes [...] lidar com todas essas mudanças, aulas online e a realização das atividades longe do professor. Muitos deixam de fazer as atividades, alguns por falta de acesso, outros não conseguem e então desistem” (Docente 4, comunicação pessoal, junho 15, 2020). Ademais, considerando a realidade indígena, "sem acesso à internet, os pais não ajudam porque trabalham ou por não possuírem estudos nem 
acesso à tecnologia digital, e há a dificuldade de compreensão por causa da língua [...]" (Docente 3, comunicação pessoal, junho 15, 2020). Considerando ainda esta problemática,

Todos sabemos que a educação é um direito de todos, e infelizmente neste tempo de pandemia a maior dificuldade encontrada pelos nossos alunos é justamente não terem os recursos que são fundamentais para a aprendizagem, falta de material adequado como livros, materiais essenciais, computadores com internet para pesquisas e estudos, até mesmo aquelas crianças que muitas vezes vão para a escola para terem a sua única refeição do dia. (Docente 6, comunicação pessoal, junho 15, 2020).

Além do acesso aos recursos tecnológicos, é preciso mencionar algo ligado diretamente à questão econômica, que é a perda de renda familiar, a qual já era insuficiente para muitos e está diminuída. Essa questão acaba fazendo com que estudantes tenham que trabalhar para ajudar a complementar a receita da família, o que configura um problema, pois o ideal neste momento é o isolamento social e não o ingresso no mercado de trabalho, e por isso muitos alunos estão dando este ano como perdido e abandonando seus estudos. Isso pode parecer uma questão de escolha, mas, na verdade, como discutido em Rodrigues (2017), é um processo de exclusão sofrido pelos estudantes, neste caso, em particular, induzidos por sua situação socioeconômica precária. Também, é necessário pontuar aqui uma questão grave no Brasil que, para muitos, ir à escola representa saciar a fome. Outra questão é a Educação Escolar de alunos com deficiência. Neste caso, fica até mais evidente

A dificuldade que o aluno tem para baixar o aplicativo, habilitar o e-mail, [...] a [falta de] aprendizagem do aluno e a falta de compreensão do conteúdo [...]. Mas a turma de AH/SD é outra realidade [...]. Foi preciso fazê-los compreender como está sendo o ensino agora, incluí-los nesse formato remoto, deixá-los tranquilos com toda a situação do ensino, para então iniciar o atendimento da sala de recursos. Como estes alunos estão na condição de habilidosos e talentosos, aparentam [...] que sabem se virar sozinhos, e na verdade não, precisam de muita ajuda para sentirem-se inseridos nessa nova realidade. (Docente 1, comunicação pessoal, junho 11, 2020).

As dificuldades em relação a interação virtual entre professores e alunos, a compreensão das atividades propostas pelos professores nos ambientes online e a motivação e disciplina dos estudantes para prosseguir com estudos durante a pandemia podem ser maximizadas quando estes alunos apresentam necessidades educacionais especiais. Os desafios impostos aos professores para o planejamento de aulas, para que todos aprendam juntos, assim como discutem Lübeck \& Rodrigues (2013), Rodrigues \& Lübeck (2018) e Klaus; Lübeck \& Silva (2018), podem ser acentuados no ambiente virtual, em que nem os professores e nem 
Donda, T. \& Lübeck, M. (2020). Escola, Educação Inclusiva e Etnomatemática em Tempos de Isolamento Social. Revista Latinoamericana de Etnomatemática, 13(1), 293-316. DOI: 10.22267/relatem.20131.51

alunos estão habituados ou capacitados. Além disso, devemos levar em conta a dificuldade do oferecimento de atendimento nas atuais circunstâncias e a ausência dos profissionais de apoio, e considerar as dificuldades inerentes a condição dos alunos, pois, para muitos, dependendo da deficiência ou transtorno, o contato com os professores é imprescindível para o seu desenvolvimento, como bem apontam os trabalhos de Furlan \& Lübeck (2019) e Lippert \& Lübeck (2019) com alunos com Altas Habilidades/Superdotação - AH/SD. Já em seus domicílios, devem ser consideradas outras condicionantes sobre os alunos, onde:

As maiores dificuldades são a falta de comprometimento de muitos pais em tentar auxiliá-los em casa, e também vale lembrar que grande parte dos alunos não possuem celular próprio [...]. Quando vamos fazer nossas videoconferências alguns alunos não participam [...]. As implicações que esse distanciamento afeta é o relacionamento pessoal deles, o convívio em sociedade com pessoas diferentes, além de uma perda maior de conteúdo, visto que se estivessem em sala de aula fariam mais atividades e teriam maiores explicações [...]. (Docente 2, comunicação pessoal, junho 13, 2020).

Em resumo, podemos saber que:

Os estudantes possuem problemas de conectividade [...]. Há ainda responsáveis dos alunos que buscam instalar os aplicativos em celulares com teclado físico, que não tem nem mesmo acesso à internet. Vale constar [...] que muitas famílias ainda não possuem aparelho celular e em muitos casos somente um membro possui e não tem internet. É válido salientar que o número de famílias que possuem notebook ou computador é muito baixa. [...]. Nem todos conseguem acompanhar as aulas online, pois possuem uma nova rotina. Alguns estudantes passaram a cuidar de crianças menores, fazer e auxiliar no serviço doméstico. [E a sua] alimentação tem sido um fator preocupante também [...]. (Docente 7, comunicação pessoal, junho 15, 2020).

Na quinta questão, perguntamos: Como a Etnomatemática, que leva em consideração as diferentes formas de conhecimento dos alunos, pode ser mobilizada e como a Educação Matemática pode ser praticada nestes contextos socioculturais distintos?. Destacamos que os docentes entendem e reconhecem a importância da Etnomatemática, e que a maioria está tentando mobilizá-la junto às suas práticas nas aulas de matemática, e na medida do possível, desenvolver uma Educação Matemática da melhor qualidade, seguindo preceitos inclusivos e com respeito e valorização dos contextos e da cultura dos educandos. De fato:

Vejo a Etnomatemática claramente presente nesse novo formato de ensinar, estamos fazendo a matemática para grupos diferentes de alunos, com conhecimentos diferentes, os quais tornaram-se evidentes. A realidade social nunca esteve tão próxima dos nossos olhos como nesse momento. Estou colocando a Educação Matemática em destaque a todo instante, estou procurando meios para ensinar matemática de forma muito mais 
humanizada do que fazia; é momento de reinventar, aprender para ensinar matemática das mais diversas formas. (Docente 1, comunicação pessoal, junho 11, 2020).

Neste excerto sentimos o engajamento em aprender para tornar as aulas mais humanizadas, e apesar do distanciamento social, isto fez com que a realidade dos alunos ficasse próxima, evidenciada, assim como suas diferenças, oportunizando um momento para se reinventar. "Eis que neste ínterim desponta a Educação Etnomatemática, a qual pretende, dentre outros objetivos, devolver para a Educação Matemática uma das suas características mais marcantes, ou seja, de ser uma manifestação designadamente humana e multifacetada [...]" (Rodrigues \& Lübeck, 2013, p. 176), isso porque, segundo afirma Vergani (2007, p. 42), “a Educação Etnomatemática - lidando com a inteireza racional, psíquica, emocional, social e cultural do homem - é uma postura criativa que ecoa a diferentes níveis e segundo diferentes graus de profundidade”. Ademais “a Educação Etnomatemática é uma 'Educação para o ambiente' [...]”' (p. 45). Com efeito,

Agora mais do que nunca [...] temos que pensar em trazer o conteúdo de uma forma com que seja totalmente voltado à vivência do aluno, de sua família, do seu dia a dia, elaborando atividades e conteúdos que valorizem a produção do conhecimento individual, buscando analisar sistematicamente a sua construção coletiva, desenvolvida através das relações do indivíduo e sua comunidade. (Docente 6, comunicação pessoal, junho 15, 2020).

A ideia de levar os conteúdos direcionados à realidade dos alunos, nos termos descritos, parece ser boa, contudo, é preciso discernimento, pois “o alheamento de práticas inerentes à cultura cotidiana é de extremo prejuízo para a Educação e, cabe também aos educadores se sensibilizarem para integrar conscientemente estes processos, sem é claro, constituir outro filtro de seleção social” (Lübeck \& Rodrigues, 2011, p. 146). Portanto,

Utilizar os preceitos do Programa Etnomatemática é pensar novas formas de ensinar matemática, é pensar no aluno primeiramente e não nos conteúdos, é promover uma Educação Matemática específica e diferenciada, e tornar os saberes cotidianos dos alunos parte do processo de escolarização matemática. (Docente 3 , comunicação pessoal, junho 15, 2020).

Como vemos, os docentes propõem "uma abordagem aberta à Educação Matemática, com atividades orientadas, motivadas e induzidas a partir do meio, e, consequentemente, refletindo conhecimentos anteriores. Isso nos leva ao que chamamos de Etnomatemática e que restabelece a matemática como uma prática natural e espontânea” (D’Ambrosio, 1998, 
Donda, T. \& Lübeck, M. (2020). Escola, Educação Inclusiva e Etnomatemática em Tempos de Isolamento Social. Revista Latinoamericana de Etnomatemática, 13(1), 293-316. DOI: 10.22267/relatem.20131.51

p. 31). Como exemplo, seguem excertos de duas atividades descritas nos feedback de dois docentes. A primeira que destacamos traz que:

A atividade contempla os temas contemporâneos Educação Financeira e Educação Fiscal, nela utilizo as contas de água e de energia elétrica para discutir matemática e uma opinião crítica de tudo que pagamos nessa sociedade capitalista [...]. Nessa atividade, trabalhamos desde a escrita de números a comparação dos números que aparecem ali. Provocando a análise na conta de energia elétrica dos valores dos campos 'total a pagar', 'compra de energia' e 'base de cálculo', e ainda, em siglas existentes como PIS, COFINS e ICMS. E na conta de água os números nos campos 'consumo', 'média', 'faixa de consumo', e outros. É pegar vários dados, discutir sobre eles e como isso interfere no dia a dia e como isso foi imposto a nós. E, ainda, em um ambiente online, onde a atividade é colocada no Google sala de aula, todos podem verificar, comentar, divulgar e contestar. (Docente 5, comunicação pessoal, junho 15, 2020).

Essa atividade vem ao encontro de outros trabalhos realizados na Educação Básica com o intuito de fazer com que os alunos compreendam e percebam a aplicação da Matemática em seu cotidiano, além de fazê-los conhecer e refletir sobre seus direitos e deveres fiscais neste mundo capitalista, como apontam os estudos de Medeiros; Lübeck; Lins \& Andretti (2019) e Andretti; Wichnoski; Lübeck \& Bassoi (2019). Já a segunda atividade mostra que:

Como estou com pouca interação online por parte dos estudantes, não conseguindo executar uma boa aula, esse trabalho não tem sido feito. $\mathrm{O}$ que tem sido feito é a tentativa de trazer alguns temas que estão sendo repercutidos como consequência da pandemia, a saber, apresentei uma aula sobre razão e proporção na primeira semana, já na segunda semana propus leitura de gráficos e tabelas sobre crimes de racismo e feminicídio. Apresentei o jogo mancala para uma turma e o software GeoGebra para outra, mas não tive em nenhum caso uma interação com os saberes emanados deles. Sinto que estou dando aula para uma sala vazia e ainda não havia parado para refletir sobre isso. Acredito na possibilidade de promover desobediências diante das tantas recomendações que me anestesiaram e buscar [...] movimentos que provoquem sensações de desconcerto nos estudantes e fazê-los explorar os próprios saberes e aproximá-los de discussões centrais dessa pandemia. Ainda nas aulas presenciais iniciamos algumas discussões que [...] denunciaram o sistema dizendo que a escola tem atitudes racistas, homofóbicas e sexistas. Diante disso, iniciamos um movimento para discutir isso em aulas de matemática, mas foi interrompido pela pandemia. Então, cabe a nós educadores matemáticos e de todas as áreas, pensar rapidamente em como abordar questões emergentes propostas por esses alunos em nossas aulas. (Docente 7, comunicação pessoal, junho 15, 2020).

Aqui, chamamos a atenção para o fato de que, "como cremos que educar matematicamente é ir além da transmissão de conteúdos - é transcender a barreira das disciplinas e construir consciência crítica em âmbito social, cultural e político - [....] nos reorganizamos e seguimos trabalhando o mundo em conjunto" (Lübeck \& Rodrigues, 2011, p. 150). Esta 
parece ser também a proposta deste docente, que está tentando trabalhar de modo variado, com temas e recursos diferentes, mas que sente a falta dos alunos. Suas iniciativas são boas, as pautas levantadas, especialmente antes da pandemia, são extremamente importantes, mas sua sala de aula está vazia, tanto a presencial quanto a virtual, ao que parece, e isto faz com que queira romper limites e tirar da inércia discussões, saberes e pessoas para movimentar suas classes de Matemática. Este é o espírito de um educador, etnomatemático e inclusivo: saber/fazer diferente e ser/conviver ativo. Com isso, "[...] queremos dizer que a postura de um educador da Educação Inclusiva na perspectiva da Educação Etnomatemática que concebemos é mais do que a de um ingênuo professor que simplesmente cumpre prazos, currículos, horários além de todas as outras obrigações [...]” (Lübeck \& Rodrigues, 2013, p. 20). É uma mobilização que ecoa, em diferentes os sentidos, uma Educação para Todos.

Entretanto, também acontece que, em algumas escolas e Secretarias de Educação - SED,

[...] não está sendo levado em consideração a Etnomatemática, pois as mesmas atividades são dispostas para realidades diferentes, ou seja, a equipe de educação faz [...] uma atividade [...], porém essa atividade é oferecida para todas as escolas [...], cada realidade deveria ter uma equipe responsável, pois, muitas vezes, os conhecimentos de estudantes [...] estão sendo deixados de lado, além do mais, o melhor a se fazer é reformular as atividades, [...] fortalecendo os conhecimentos já adquiridos pelos discentes. (Docente 2, comunicação pessoal, junho 13, 2020).

Nisto, apesar de ficar claro que a realidade de todos os alunos não está sendo considerada, o docente tem consciência disto e sugere que o melhor a fazer é reformular o que vem pronto. Essa ideia é corroborada por Knijnik; Wanderer; Giongo \& Duarte (2012, p. 66) quando afirmam que trazer a realidade dos alunos "[.... para as aulas de matemática é importante para transformar socialmente o mundo [...] [e] dar significado aos conteúdos, suscitando o interesse dos alunos por aprender." Agora, mais do que nunca, isso é algo muito necessário. Por fim, sobre o Espaço aberto para comentários, chamamos a atenção para o fato de que,

Atualmente, estamos vendo e vivenciando um tempo em que estamos cada vez valorizando mais nosso trabalho, vemos o quanto somos indispensáveis, e como trabalhar a matemática com alunos que estão em uma realidade totalmente diferente, que muitas vezes não conhecem outra vida a não ser a que vive dentro de suas comunidades, e como agir neste momento, não há outra forma a não ser trabalhar a matemática voltada para o conhecimento que faça relação com a vida do indivíduo, o ensinando a utilizar a matemática para seu próprio bem, para seu uso dentro de sua família e sua comunidade, para seu bem pessoal. (Docente 6, comunicação pessoal, junho 15, 2020). 
Além disso, no que se refere a ação docente propriamente dita, “[...] as medidas estão sendo tomadas conforme as possibilidades [...], porém as dificuldades são maiores quando se tem alunos de 06 a 11 anos, pois ainda não possuem amadurecimento para a educação que não seja presencial" (Docente 2, comunicação pessoal, junho 13, 2020). Outrossim, por um lado, "um ponto positivo [...] é a Secretaria de Educação [...] afirmar que teremos perdas de aprendizagem e o que não pode acontecer é o aluno perder a prática de escolarização [...]”, por outro lado, "um ponto negativo [...] é a formação que a SED oferece e está oferecendo, [...] cursos sem fundamentação teórica (não existe quem disse e provou isso) e que todos os problemas se resolvem na prática e boa vontade" (Docente 5, comunicação pessoal, junho 15, 2020). Ademais, "nesse momento de solidão provocada pelo distanciamento social, as questões [...] me colocaram a refletir sobre o que tem acontecido enquanto estamos 'distraídos e exaustos'. Pode ser um movimento que [...] usa nossos corpos para resolver problemas do capitalismo" (Docente 7, comunicação pessoal, junho 15, 2020). Eis daí uma questão: "Por que todos não tem acesso a um aparelho celular com acesso a internet e a SED está investindo tanto em plataforma digital [...], e-mail institucional com ferramentas ilimitadas (Drive ilimitado) e pacotes de programas ilimitados?” (Docente 5, comunicação pessoal, junho 15, 2020). Pensando nisso, resta perguntar: Seria essa mais uma entre tantas artimanhas ou manobra política e econômica que beneficia mais os que menos precisam e menos os que mais precisam? As respostas a estas perguntas, na verdade, só o tempo trará!

\section{CONSIDERAÇÕES FINAIS}

Neste artigo mostramos indícios de como a Educação Escolar está tentando acontecer neste algoz momento de pandemia e isolamento social, analisando os resultados de uma pesquisa realizada com docentes da Educação Básica atuantes em contextos da Educação Escolar Indígena, Educação Escolar do Campo, Educação Especial e Inclusiva, Educação de Jovens e Adultos, entre outras, de diferentes municípios e regiões do Brasil. Por meio dos seus relatos, ao responderem o questionário que lhes enviamos remotamente, soubemos quais os desafios e as implicações educacionais enfrentadas pelos educadores e educandos, como a Educação Matemática está sendo praticada e como a Etnomatemática pode ser mobilizada. Dos excertos saíram os dados da pesquisa que apreciamos de maneira qualitativa, e sobre os quais teorizamos na perspectiva da Educação Inclusiva. Vimos que os professores estão 
ativos, assim como suas escolas, e suas ações orbitam em torno de aulas remotas com o uso de diferentes tecnologias; e vimos também que as limitações tecnológicas, socioculturais e humanas têm dificultado a inclusão de todos os alunos, apesar dos esforços empreendidos. Ao compartilharem seus relatos, fizemos das suas palavras também as nossas. Desse modo, apresentamos reflexões na fraseologia dos docentes em seus próprios termos, porque são reais, são concretos, e não precisam de maiores argumentações e articulações para ajudar a expressar o que verdadeiramente dizem. A nossa contribuição agora é promover que sejam lidas por outras pessoas, para que todos conheçam o que vivem e fazem estes docentes. Que alternativa mais podemos oferecer para aqueles que com muita criatividade, determinação e resiliência estão na linha de frente das escolas senão prestar-lhes essa consideração? Ainda: Por que eleger pontos para problematizar entre os relatos trazidos se tudo é assaz relevante? Chamar à baila quem está num platô para que se junte a peleja por dias melhores talvez seja uma possibilidade. Do resto estes docentes falaram. E as temáticas e unidades significativas estão sintetizadas numa nuvem de palavras na Figura 1.

No entanto, devemos lembrar que os problemas educacionais não se resolvem somente com uma prática ou boa vontade. Precisa ter investigação, organização, capacitação tecnológica, conhecimento, condições mentais, materiais, sanitárias e políticas, diálogo, tempo etc. E que de pitacos na Educação os professores estão saturados. De ordens e cursos estéreis por quem não conhece a realidade das escolas e dos alunos igualmente. Contudo, pensando na possibilidade de a Etnomatemática contribuir no combate à crise que vivemos na pandemia, é preciso ressaltar que, longe do olho no olho, do estar junto, pelas salas de aulas vazias e perante as carências dos alunos é difícil vislumbrar alguma coisa que possa transcender a mera transmissão online ou impressa de conteúdos. Apesar disso, sabemos que este não é um caminho legítimo para uma Educação para Todos. Nessa perspectiva, os docentes estão adiantados e certos ao engendrar esforços para tornar as aulas sempre mais humanizadas, implementando distintas ações para os diferentes grupos, considerando distintos saberes e fazeres, onde os conteúdos estão sendo voltados para as vivências de cada um, integrando o conhecimento dos mesmos no processo de escolarização, e com isso, quiçá reestabelecendo a matemática como algo natural, com atividades ambientadas, interessantes, atuais e úteis, fortalecendo a cultura dos alunos e outras formas de ser, conhecer, atuar e conviver, pois 
como aprendemos alhures, a Etnomatemática se vive e se faz. Portanto, o que compete ao Programa Etnomatemática além de procurar entender o ser/saber/fazer/conviver humano contextualizado em diferentes grupos sociais e culturais?

A propósito, a Etnomatemática é um programa de pesquisa e não um projeto curativo que examina, diagnostica e prescreve receitas. Isso é outra coisa. As lentes da Etnomatemática, assim como as da Educação Inclusiva, nos permitem olhar o mundo de uma maneira crítica, transcultural, transdisciplinar e holística, reconhecendo e respeitando as raízes culturais das pessoas. Então, o bom senso sugere que qualquer docente desenvolva com os seus alunos o fortalecimento dessas raízes, seguindo uma ética de respeito, solidariedade e cooperação. Que contextualize a Matemática, que assuma que seus alunos são mais importantes que os conteúdos e que compreenda que os últimos somente justificam fazerem parte da Educação Escolar quando conseguem melhorar a vida das pessoas, algo que precisamos muito agora. Isto nos fez lembrar de uma valiosa fábula, a qual diz que, certa vez, houve um incêndio na floresta, e enquanto a maioria dos seres fugiam, um pequeno beija-flor voava do rio ao fogo levando água em seu bico na intenção de apagar as chamas. Os que estavam fugindo lhe perguntaram se ele pensava que iria apagar o fogo sozinho. Este de pronto então respondeu: “- Eu não sei se vou conseguir apagar todo fogo sozinho, mas estou fazendo a minha parte.” Pensando nisso, no beija-flor que voa em todas as direções; que ao mesmo tempo em que se fortalece bebericando a seiva de uma flor também poliniza outras tantas; e nesta fábula, em que incansavelmente luta contra o ardor, enquanto muitos fogem, outros morrem e alguns carniceiros se alegram, nos parece que os elementos são mais concretos do que alegóricos. Por isso, “se cuidem e fiquem bem!” (Docente 1, comunicação pessoal, junho 11, 2020). 


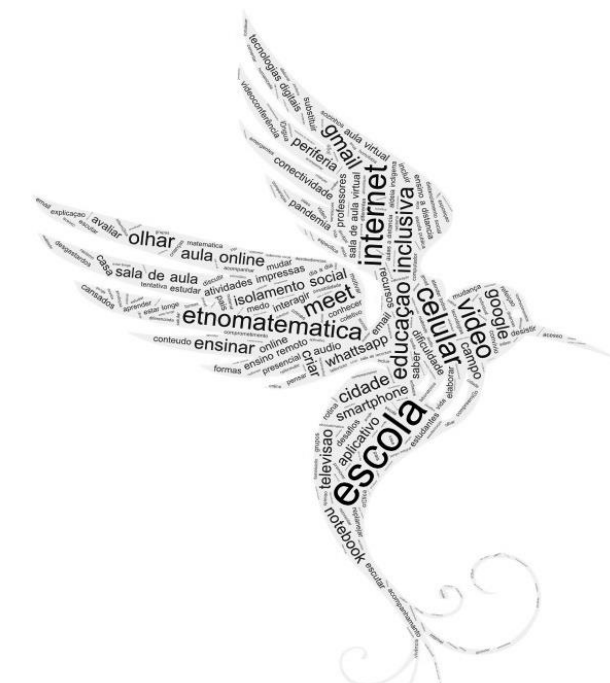

Figura 1. Palavras destacadas nos discursos docentes.

Fonte: autores, 2020.

\section{REFERÊNCIAS}

Andretti, F., Wichnoski, P., Lübeck, M., \& Bassoi, T. (2019). Sequência Didática para o Ensino de Estatística Descritiva com Recurso à Metodologia da Problematização. Anais do XIII Encontro Nacional de Educação Matemática, Cuiabá, Brasil. Recuperado de https://bityli.com/krVn0.

Bogdan, R., \& Biklen, S. (2006). Investigação Qualitativa em Educação: uma introdução à teoria e aos métodos. Porto: Porto.

Comitê Gestor da Internet no Brasil. (2019). Pesquisa sobre o uso das tecnologias da informação e comunicação nos equipamentos culturais brasileiros - TIC Cultura 2018. São Paulo: CGI.br.

D’Ambrosio, U. (1998). Etnomatemática: arte ou técnica de explicar e conhecer. São Paulo: Ática.

D'Ambrosio, U. (2002). Etnomatemática: elo entre as tradições e a modernidade. Belo Horizonte: Autêntica.

D’Ambrosio, U. (2018). Etnomatemática, Justiça Social e Sustentabilidade. Estudos Avançados, 32(94), 189-204. Recuperado de https://bityli.com/BrntI.

D’Ambrosio, U. (2004). Prefácio. En M. Borba \& J. Araújo (Eds.), Pesquisa Qualitativa em Educação Matemática (pp. 11-23). Belo Horizonte: Autêntica.

Fiorentini, D. \& Lorenzato, S. (2006). Investigação em Educação Matemática: percursos teóricos e metodológicos. Campinas: Autores Associados. 
Furlan, W. \& Lübeck, M. (2019). O Papel do Professor Frente ao Fenômeno das Altas Habilidades/Superdotação em Matemática. Anais do XV Encontro Paranaense de Educação Matemática, Londrina, Brasil. Recuperado de https://bityli.com/kdsaT.

IBGE. (2018). Pesquisa Nacional por Amostra de Domicílios Contínua - PNAD 2018. Recuperado de https://www.ibge.gov.br.

Kaminski, M., Ribeiro, R., Lübeck, M. \& Boscarioli, C. (2019). Tecnologias Digitais para o Ensino de Matemática nas Escolas Indígenas: importância e dificuldades. $e$ Mosaicos, 8(17), 98-113. Recuperado de https://bityli.com/rLIxD.

Klaus, V., Lübeck, M. \& Silva, P. G. (2018). Da Universidade à Escola: a diversidade presente na sala de aula. Revista Eletrônica de Educação, 12(2), 530-543. Recuperado de https://bityli.com/BQnlf.

Knijnik, G., Wanderer, F., Giongo, I. M. Duarte, C. G. (2012). Etnomatemática em Movimento. Belo Horizonte: Autêntica.

Lippert, V. \& Lübeck, M. (2019). Alunos com Altas Habilidades/Superdotação Interagindo como Monitores no Ensino de Álgebra. Anais do XIII Encontro Nacional de Educação Matemática, Cuiabá, Brasil. Recuperado de https://bityli.com/pzelx.

Lübeck, M. \& Rodrigues, T. (2011). Desafios para a Educação Etnomatemática. En A. M. PRADO et al. (Eds.). Práxis Educacional, Direitos Fundamentais e Política (pp. 145-152). Curitiba: CRV.

Lübeck, M. \& Rodrigues, T. D. (2013). Incluir é Melhor que Integrar: uma concepção da Educação Etnomatemática e da Educação Inclusiva. Revista Latinoamericana de Etnomatemática, 6(2), 8-23. Recuperado de https://bityli.com/Vacl1.

Lüdke, M. \& André, M. (2003). Pesquisa em Educação: abordagens qualitativas. São Paulo: EPU.

Medeiros, E. \& Amorim, G. (2017). Análise Textual Discursiva: dispositivo analítico de dados qualitativos para a pesquisa em educação. Laplage em Revista, 3(3), 247-260. Recuperado de https://bityli.com/Chuwg.

Medeiros, J., Lübeck, M., Lins, G. \& Andretti, F. (2019). Matemática e Educação Fiscal: $5^{\circ}$ ano do ensino fundamental. Anais do XV Encontro Paranaense de Educação Matemática, Londrina, Brasil. Recuperado de https://bityli.com/z3VQg.

Moraes, R. \& Galiazzi, M. C. (2006). Análise Textual Discursiva: processo reconstrutivo de múltiplas faces. Ciência \& Educação, 12(1), 117-128. Recuperado de https://bityli.com/Mrlf1.

Moreira, M. A. (2011). Metodologias de Pesquisa em Ensino. São Paulo: LF.

Oliveira, M. M. (2014). Como Fazer Pesquisa Qualitativa. Petrópolis: Vozes.

Rodrigues, T. D. (2017). Práticas de Exclusão em Ambiente Escolar. São Paulo: Cultura Acadêmica. 
Rodrigues, T. \& Lübeck, M. (2013). A Educação Etnomatemática e a Formação de Professores. En D. A. C. Araújo \& A. Souza (Eds.). Políticas Públicas na Contemporaneidade (pp. 175-184). Curitiba: CRV.

Rodrigues, T. \& Lübeck, M. (2018). Contribuições da Etnomatemática para uma Educação Inclusiva. Memorias del $6^{\circ}$ Congreso Internacional de Etnomatemática: saberes, diversidade e paz, Medellín, Colômbia.

Shimazaki, E., Menegassi, R., \& Fellini, D. (2020). Ensino Remoto para Alunos Surdos em Tempo de Pandemia. Práxis Educativa, 15(e2015476). 1-17. Recuperado de https://bityli.com/j6xwG.

UNESCO. (1990). Declaração Mundial sobre Educação para Todos: satisfação das necessidades básicas de aprendizagem. Jomtien, Tailândia.

UNESCO. (2005). Guidelines for Inclusion: ensuring access to Education for All. Recuperado de https://bityli.com/76693.

UNESCO. (2020). Relatório de Monitoramento Global da Educação - resumo - 2020: Inclusão e Educação: todos, sem exceção. Recuperado de https://bityli.com/Wnlde.

UNICEF. (2018). Pobreza na Infância e na Adolescência. Brasil. Recuperado de https://bityli.com/UDVzx.

Vergani, T. (2007). Educação Etnomatemática: o que é? Natal: Flecha do Tempo. 